\title{
Splenectomy delays fracture healing by affecting the level of tumor necrosis factor alpha, interleukin 6 and bone morphogenetic protein
}

\author{
Wanan Xiao ${ }^{A-D}$, Xiaoxiao Yang ${ }^{B-D}$, Yang Wang ${ }^{B, C}$, Jianjun Li ${ }^{A-F}$ \\ Department of Orthopedics, Shengjing Hospital of the China Medical University, Shenyang, China \\ A - research concept and design; $\mathrm{B}$ - collection and/or assembly of data; $\mathrm{C}$ - data analysis and interpretation; \\ $D$ - writing the article; $E$ - critical revision of the article; $F$ - final approval of the article
}

Address for correspondence

Jianjun Li

E-mail: lijianjun_sy2015@sina.com

Funding sources

None declared

Conflict of interest

None declared

\section{Acknowledgements}

The present project was supported by

Liaoning Provincial Natural Science Foundation

(№.201602836).

Received on August 31, 2016

Reviewed on September 22, 2016

Accepted on December 15, 2016

\begin{abstract}
Background. Abdominal injuries combined with bone fractures are increasing. Splenectomies are often required, but have prolonged healing time for bone fracture.

Objectives. The aim of the study was to explore the molecular mechanism for splenectomy delaying fracture healing.

Material and methods. Eighty-four patients (42 received splenectomy) who received hip fractures operations were recruited in our hospital. One-year follow-up analysis was performed. To ensure the results, an animal model was established. Spraque-Dawley (SD) rats were randomly divided into 5 groups: group A: experimental group, femoral fractures + splenectomy; group B: femoral fractures; group C: splenectomy; group D: femoral fracture + sham splenectomy; group E: sham fracture. After the femoral fracture surgery, the callus status was evaluated by $X$-ray.
\end{abstract}

Results. After 1-year follow-up, the healing index and bone quality was higher in the fracture-operatedonly group than in the splenectomy group. In contrast, the rate of healing complications was lower in the fracture-operated-only group than in the splenectomy group. Biomarker analysis showed that the serum levels of tumor necrosis factor alpha (TNF-a), interleukin 6 (IL-6) and bone morphogenetic protein (BMP) were higher in the fracture-operated-only group than in the splenectomy group. No difference of the callus status was found among the rats in groups $B, D$ and $E(p>0.05)$, while there were significant differences of the callus status of the rats in groups $A$ and $C$ at different stages $(p<0.05)$. On the other hand, the levels of TNF-a, IL-6 and BMP increased, reached peak after 7-day splenectomy surgery, and then decreased significantly in groups $A$ and $C(p>0.05)$.

Conclusions. Splenectomy delays fracture healing by affecting the levels of TNF-a, IL-6 and BMP.

Key words: immune function, splenectomy, fracture, tumor necrosis factor-alpha, bone morphogenetic protein

DOI

10.17219/acem/67755

\section{Copyright}

Copyright by Author(s)

This is an article distributed under the terms of the

Creative Commons Attribution Non-Commercial License

(http://creativecommons.org/licenses/by-nc-nd/4.0/) 


\section{Introduction}

Abdominal injuries combined with bone fractures caused by accident are increasing. ${ }^{1}$ Spleen rupture accounts for $20-40 \%$ of blunt abdominal trauma cases. In many cases, splenectomies are required to save the patients' life. Follow-ups have found that patients with splenectomy have prolonged healing time for bone fractures.

During the bone formation process, there is a balance between osteoblast activity and osteoclast activity. The role of osteoblasts is to synthesize the bone matrix, and they are differentiated from the mesenchymal stem cells; the role of osteoclasts is to degrade the bone matrix, and they are differentiated from bone marrow mononuclear macrophages. The fracture healing process requires a lot of new osteoblasts,which help speed up bone synthesis and increase bone volume and density. ${ }^{2}$

Bone fracture healing is a complex process of bone regeneration, in which immune factors may play important roles. ${ }^{3,4}$ Cytokines, a group of proteins known to regulate hemopoietic and immune activities, have been found to be involved in fracture healing. ${ }^{5}$ The interleukin 6 (IL-6) polymorphism has been found to be associated with fracture risk. Meta-analysis shows that the IL-6-174 C/G polymorphism is related to the risk of wrist and osteoporotic fracture. ${ }^{6}$ Multiple studies show that TNF- $\alpha$, in combination with the host reservoir of perifracture mesenchymal stem cells, is associated with bone healing. ${ }^{7}$ Bone morphogenetic protein (BMP) is a kind of multi-functional growth factor which belongs to the transforming growth factor beta (TGF- $\beta$ ) superfamily. High-level expression of BMP improves bone callus formation and shortens the time of bone fracture healing. ${ }^{8}$ In this study, delayed bone healing was found in the fracture-operated patients who also received splenectomy. Furthermore, an experimental animal splenectomy model was used to investigate the effects of immune function changes after splenectomy on fracture healing in a rat model.

\section{Material and methods}

\section{Patients}

All procedures were approved by the ethics committee of Shengjing Hospital of China Medical University (Shenyand, China). From May 2, 2010 to July 7, 2015, all hip fracture patients were reviewed at our hospital. Patients with the following diseases were excluded: osteomalacia, vitamin D deficiency and hyperthyroidism, as they can affect the normal development of bone. The hip fracture patients who also received splenectomy were selected as the splenectomy group (SFG), according to the International Statistical Classification of Diseases and Related Health Problems v. 9, Clinical Modification (ICD-9-CM). 9,10 Participants without splenectomy were randomly selected as the "hip-fracture-only group" (FG). The 2 groups were matched by sex, age and baseline characteristics (Table 1). A total of 84 patients (42 received splenectomy) who received a hip fracture operation in our hospital were selected.

\section{Bone quality analysis}

Bone quality at a non-fracture site was assessed according to the criteria offered by Singh. ${ }^{11}$ Bone quality is classified by 6 grades: from grade 1 (poor bone quality) to grade 6 (normal bone quality).

\section{Healing complications}

Fracture healing complications were investigated after surgical repair and after up to 1 year. The complications included the rates of infection, delayed union and surgical re-intervention.

\section{ELISA analysis of bone healing biomarkers in serum}

The ELISA kits used to analyze the serum levels were the Human TNF-alpha ELISA Kit (ab46087), Human IL-6 ELISA Kit (ab46042) and Human BMP-2 ELISA Kit (ab119581). All the kits were purchased from Abcam Trading Company Ltd. (Shanghai, China).

\section{Animals}

To investigate the molecular mechanism for splenectomy delaying fracture healing, an animal model was established and the main molecules were examined. Healthy 12-week-old Sprague-Dawley (SD) rats (SPF grade, body weight: $300 \pm 35$ g) were provided by Shengjing Hospital of China Medical University Experimental Animal Center. They were randomly divided into 5 groups $(n=8$ for each group) by random number table: group A: femoral fractures + splenectomy; group B: femoral fractures only; group C: splenectomy only; group D: femoral fracture + sham splenectomy; group E: sham fracture. The rats were housed in the Experimental Animal Center, Shengjing Hospital of China Medical University. This study was approved by the Ethics Committee of Shengjing Hospital of China Medical University (2013PS11K).

\section{Surgical methods}

Femoral fractures were made by a $0.8 \mathrm{~mm}$ diameter wire saw. After anesthesia, a lateral femoral incision of about $2.5 \mathrm{~cm}$ was made in the left leg of the rat. Through the skin incision and intermuscular space, the full-length femur was exposed, and then a transverse fracture was made at the midpoint of the femoral shaft using a $0.8 \mathrm{~mm}$ diameter wire saw, followed by fixation with a 2.0 intramedullary 
Kirschner wire. After washing with povidone-iodine and saline, the muscle and skin were sutured. In the femurfracture sham group, a suture was performed after just exposing and disinfecting the femur.

After anesthesia and skin preparation, with the rat in the right lateral position, a vertical incision was made at $1.5-2.0 \mathrm{~cm}$ under the left costal arch. Under sterile conditions, the stomach was put to the right to dissociate the spleen (a long strip of about $4 \mathrm{~cm}$ ), and then the splenic arteries were clamped and cut off (about 4-6 arteries, arranged in parallel). Finally, the spleen was removed and the cut was sutured. The splenic arteries in the sham group were briefly exposed but not cut off, and the spleen was not removed.

\section{Radiography}

Digital radiography (DR) of the femur was performed to evaluate the femur status. All the images were analyzed as grayscale density by using Image-Pro-Plus 6.0 (Media Cybernetics Inc., Rockville, USA). The bone callus areas were analyzed in the DR images. Callus grayscale rates were calculated as ratios of the grayscale densities of the callus area to those of the normal bone areas. After surgery, the rats in groups $\mathrm{A}, \mathrm{B}$ and $\mathrm{D}$ underwent digital radiography on day $7,14,28,42,56,70$, and 84 .

\section{Real-time polymerase chain reaction}

A blood sample $(1.0 \mathrm{~mL})$ was taken via the orbital venous plexus, placed in a sterile EP tube with EDTA, and preserved under $4^{\circ} \mathrm{C}$. The extraction of total RNA was performed with a TaKaRa extraction Kit (Takara Bio, Dalian, China) according to the manufacturer's instructions. The extracted RNA had an OD260/OD280 ratio of 1.7-2.0.

To $1.0 \mu \mathrm{L}$ total RNA, $2.0 \mu \mathrm{L} 5 \times$ gDNA Eraser buffer, $1.0 \mu \mathrm{L}$ gDNA Eraser, and RNase free $\mathrm{dH}_{2} \mathrm{O}$ were added to a total volume of $10 \mu \mathrm{L}$, and then the solution was kept at $42^{\circ} \mathrm{C}$ for $2 \mathrm{~min}$ to remove genomic DNA. The treated solution was mixed with $4.0 \mu \mathrm{L} 5 \times$ PrimeScript $^{\circledR}$ Buffer, $1.0 \mu \mathrm{L}$ PrimeScript ${ }^{\circledR}$ RT Enzyme Mix I, 1.0 $\mu \mathrm{L}$ RT Primer Mix and $4 \mu \mathrm{L}$ RNase free $\mathrm{H}_{2} \mathrm{O}$ at $37^{\circ} \mathrm{C}$ for $15 \mathrm{~min}$, and $85^{\circ} \mathrm{C}$ for $5 \mathrm{~s}$ for reverse transcription reaction. The resulting rDNA was finally stored at $4^{\circ} \mathrm{C}$.

Every $10 \mu \mathrm{L}$ of polymerase chain reaction (PCR) mixture contained $1 \mu \mathrm{L}$ cDNA solution, $5 \mu \mathrm{L}$ SYBR $^{\circledR}$ Premix Ex $\operatorname{Taq}^{\mathrm{TM}}(2 \times), 1 \mu \mathrm{L}$ PCR primers $(5 \mu \mathrm{M}), 3 \mu \mathrm{L} \mathrm{dH}_{2} \mathrm{O}$. A Roche LightCycler ${ }^{\circledR} 480$ II quantitative real-time PCR amplification system was used for the PCR. The mRNA levels of tumor necrosis factor alpha (TNF- $\alpha$ ), interleukin 6 (IL-6) and bone morphogenetic protein (BMP) were determined on day $0,2,7,14,21,28$, and 42 .

\section{Western blot}

Protein was isolated using a protein isolation kit (Cat. No. ab65400, Abcam Trading Company Ltd.). Polyclonal rabbit anti-rat interferon alpha (ab191903), anti-rat IL-6 (ab7737), anti-rat BMP antibodies (ab118520) and goat anti-rabbit IgG H\&L (ab6721) were purchased from Abcam Trading Company Ltd. (Shanghai, China). A rabbit anti-rat $\beta$-actin polyclonal antibody (Cat No. 4967, Cell Signaling Technology, Danvers, USA) was used as a loading control. All protein bands were visualized using an enhanced chemiluminescence substrate (Sangon Biotech Co. Ltd., Shanghai, China). The image intensity of the protein band was quantified by using NIH ImageJ software (Bethesda, USA).

\section{Data analysis}

All data was presented as number, mean values $\pm S D$, and were analyzed using SPSS statistical software 20.0. Callus grayscale rates were calculated in group A, B and D. Fold induction was calculated to show the relative expression of the target gene in the experimental group. ${ }^{12}$ The $\chi^{2}$ test and Student's t-test were used to compare the 2 sets of data for determining whether there were significant differences between the 2 groups. There were statistically significant differences if $\mathrm{p}<0.05$.

\section{Results}

\section{Baseline characteristics}

After careful selection, there was no significant difference for healing index, bone quality and healing complications between SFG and FG groups ( $p>0.05)$ (Table 1). Meanwhile, other parameters were also matched between the 2 groups $(\mathrm{p}>0.05)$ (Table 1$)$.

\section{Outcome after one-year follow-up}

After 1-year follow-up, the healing index and bone quality were higher in the fracture-operated-only group than in the splenectomy group $(\mathrm{p}<0.001)$ (Table 2$)$. In contrast, the rate of healing complications was lower in the fractureoperated-only group (FG) than in the splenectomy group. The biomarker analysis showed that the serum levels of TNF- $\alpha$, IL- 6 and BMP were higher in the fracture-operated-only group than in the splenectomy group $(\mathrm{p}<0.001)$ (Table 2). Splenectomy was associated with worse calcification at the fracture site (fracture healing index $\leq 3$ ) and worse bone quality (bone quality index $>3$ ) than in the FG group $(\mathrm{p}<0.001)$ (Table 2). Moreover, patients receiving splenectomy had more complications following hip fracture fixation than those in the FG group $(\mathrm{p}<0.001)$ (Table 2). 
Table 1. Baseline characteristics of all participants

\begin{tabular}{|c|c|c|c|c|c|}
\hline \multicolumn{2}{|c|}{ Variable } & $\mathrm{FG}(\mathrm{n}=42)$ & $\operatorname{SFG}(n=42)$ & $\mathrm{x}^{2}$ statistic/t-value & $p$-value \\
\hline \multicolumn{2}{|l|}{ Gender [male/female] } & $27 / 15$ & $25 / 17$ & 0.2019 & ${ }^{\mathrm{a}} 0.653$ \\
\hline \multicolumn{2}{|l|}{ Age [years] } & $39.8 \pm 11.2$ & $40.6 \pm 10.6$ & 1.34164 & bo.114 \\
\hline \multicolumn{2}{|l|}{$\mathrm{BMl}$} & $24.8 \pm 5.6$ & $25.2 \pm 4.8$ & 0.738 & ${ }^{b} 0.244$ \\
\hline \multirow{2}{*}{ Fracture healing index } & $\leq 3$ & 3 & 2 & 0.213 & $\mathrm{a} 0.645$ \\
\hline & $>3$ & 39 & 40 & 0.213 & ${ }^{\mathrm{a}} 0.645$ \\
\hline \multirow{2}{*}{ Bone quality index } & $>3$ & 3 & 4 & 0.156 & ${ }^{\mathrm{a}} 0.693$ \\
\hline & $\leq 3$ & 39 & 38 & 0.156 & ${ }^{\mathrm{a}} 0.693$ \\
\hline \multirow{2}{*}{ Healing complications } & yes & 40 & 41 & 0.346 & ${ }^{\mathrm{a}} 0.557$ \\
\hline & no & 2 & 1 & 0.346 & ${ }^{\mathrm{a}} 0.557$ \\
\hline \multicolumn{6}{|c|}{ Baseline comorbidities } \\
\hline \multicolumn{2}{|l|}{ Cystic kidney disease } & 1 & 1 & 0 & $\mathrm{a}_{1}$ \\
\hline \multicolumn{2}{|c|}{ Human immuno deficiency virus diagnosis } & - & - & - & - \\
\hline \multicolumn{2}{|l|}{ Diabetes mellitus } & 3 & 2 & 0.213 & ${ }^{\mathrm{a}} 0.645$ \\
\hline \multicolumn{2}{|l|}{ Drug dependence } & 2 & 3 & 0.213 & ${ }^{\mathrm{a}} 0.645$ \\
\hline \multicolumn{2}{|l|}{ Urolithiasis } & 2 & 1 & 0.346 & ${ }^{\mathrm{a}} 0.557$ \\
\hline \multicolumn{2}{|l|}{ Urinary tract infection } & 1 & 1 & 0 & $\mathrm{a}_{1}$ \\
\hline \multicolumn{6}{|c|}{ Biomarker analysis } \\
\hline \multicolumn{2}{|l|}{ TNF-a [pg/mL] } & $19.4 \pm 4.8$ & $18.7 \pm 4.4$ & 0.862 & ${ }^{\mathrm{b}} 0.274$ \\
\hline \multicolumn{2}{|l|}{ IL-6 [pg/mL] } & $11.5 \pm 3.0$ & $12.1 \pm 3.6$ & 2.178 & ${ }^{b} 0.715$ \\
\hline \multicolumn{2}{|l|}{ BMP [pg/mL] } & $61.9 \pm 17.2$ & $65.3 \pm 16.5$ & 0.623 & b0.137 \\
\hline
\end{tabular}

TNF-a - tumor necrosis factor alpha; IL-6 - interleukin 6; BMP - bone morphogenetic protein; a $\mathrm{p}$-value was calculated by $\mathrm{X}^{2}$; b calculated with Student's t-test for independent samples. There were statistically significant differences if $p<0.05$. FG - hip-fracture-only patients without splenectomy were randomly selected as the fracture group; SFG - the hip fracture patients who also received splenectomy were selected as the splenectomy group.

Table 2. Analysis of bone healing after 1-year follow-up

\begin{tabular}{|c|c|c|c|c|c|}
\hline \multicolumn{2}{|c|}{ Variable } & $\mathrm{FG}(\mathrm{n}=42)$ & SFG $(n=42)$ & $\mathrm{X}^{2}$ statistic/t-value & $p$-values \\
\hline Fracture healing index & $\begin{array}{l}\leq 3 \\
>3\end{array}$ & $\begin{array}{c}38 \\
4\end{array}$ & $\begin{array}{l}23 \\
19\end{array}$ & 13.4711 & 0.001 \\
\hline Bone quality index & $\begin{array}{l}>3 \\
\leq 3\end{array}$ & $\begin{array}{c}40 \\
2\end{array}$ & $\begin{array}{l}25 \\
17\end{array}$ & 15.303 & 0.001 \\
\hline Healing complications & $\begin{array}{c}\text { yes } \\
\text { no }\end{array}$ & $\begin{array}{c}4 \\
38\end{array}$ & $\begin{array}{l}28 \\
14\end{array}$ & 29.077 & 0.001 \\
\hline \multicolumn{6}{|c|}{ Biomarker analysis } \\
\hline TNF-a [pg/mL] & & $18.7 \pm 5.8$ & $12.1 \pm 4.0$ & 6.123 & 0.002 \\
\hline IL-6 [pg/mL] & & $12.6 \pm 3.2$ & $8.7 \pm 2.9$ & 8.637 & 0.001 \\
\hline $\mathrm{BMP}[\mathrm{pg} / \mathrm{mL}]$ & & $60.1 \pm 18.6$ & $54.3 \pm 17.3$ & 9.794 & 0.001 \\
\hline
\end{tabular}

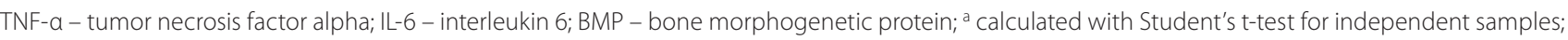
$p$-value was calculated by $x^{2}$ test. There were statistically significant differences if $p<0.05$. FG - hip-fracture-only patients without splenectomy were randomly selected as the fracture group; SFG - the hip fracture patients who also received splenectomy were selected as the splenectomy group.

\section{Fracture status of rat models}

After femur fracture, the formation of the callus was demonstrated by radiography. Figure $1 \mathrm{~A}$ shows that the callus formation was delayed. Figures 1B and 1D show that the bone callus was formed. Figures $1 \mathrm{C}$ and $1 \mathrm{E}$ show normal femur bone structure.

The changes of the grayscale intensity ratio of the callus area to normal area are shown in Fig. 2. There was a significant difference between group A and group B or $\mathrm{D}$, while the difference between group $\mathrm{B}$ and group $\mathrm{D}$ was not significant. No fracture was observed in group $C$ and group E.

\section{Relative mRNA levels of TNF- $a$, IL- 6 and $B M P$ in the rat model}

As shown in Fig. 3A, 3B and $3 \mathrm{C}$, the mRNA levels of TNF- $\alpha, I L-6$ and $B M P$ in the rats from group A and $C$ reached a peak on day 7 and then decreased. For the rats without splenectomy (groups B, D and E), the mRNA levels of TNF- $\alpha$ (Fig. 3A), IL-6 (Fig. 3B) and BMP (Fig. 3C) did 


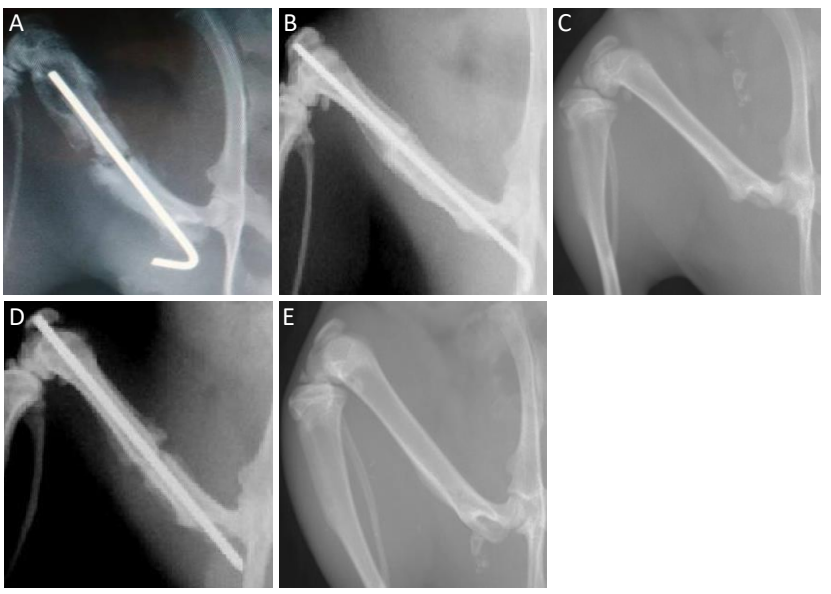

Fig. 1. X-rays show the femur of the rats 28 days after surgery

A: femoral fractures + splenectomy; B: femoral fractures only; C: splenectomy only; D: femoral fracture + sham splenectomy; E: sham fracture.

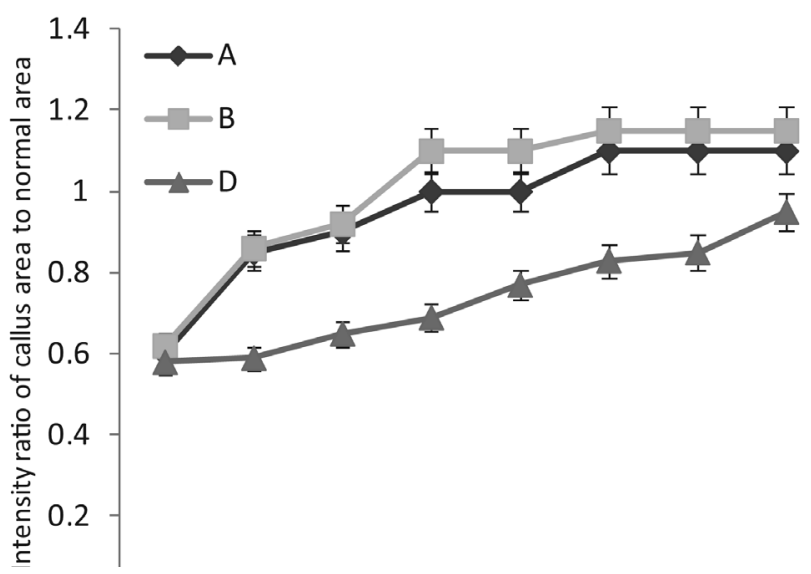

Fig. 2. Changes of the grayscale intensity ratio of the callus area to normal area in the $\mathrm{X}$-ray images

A - femoral fractures + splenectomy; B - femoral fractures only; $D$ - femoral fracture + sham splenectomy.

not show significant changes (Fig. 3C), even 42 days after surgery.

\section{Protein level of TNF- $a$, IL- 6 and BMP in the rat model}

The protein levels of TNF- $\alpha$, IL- 6 and BMP were analyzed by western blot. As shown in Fig. 4, the protein level
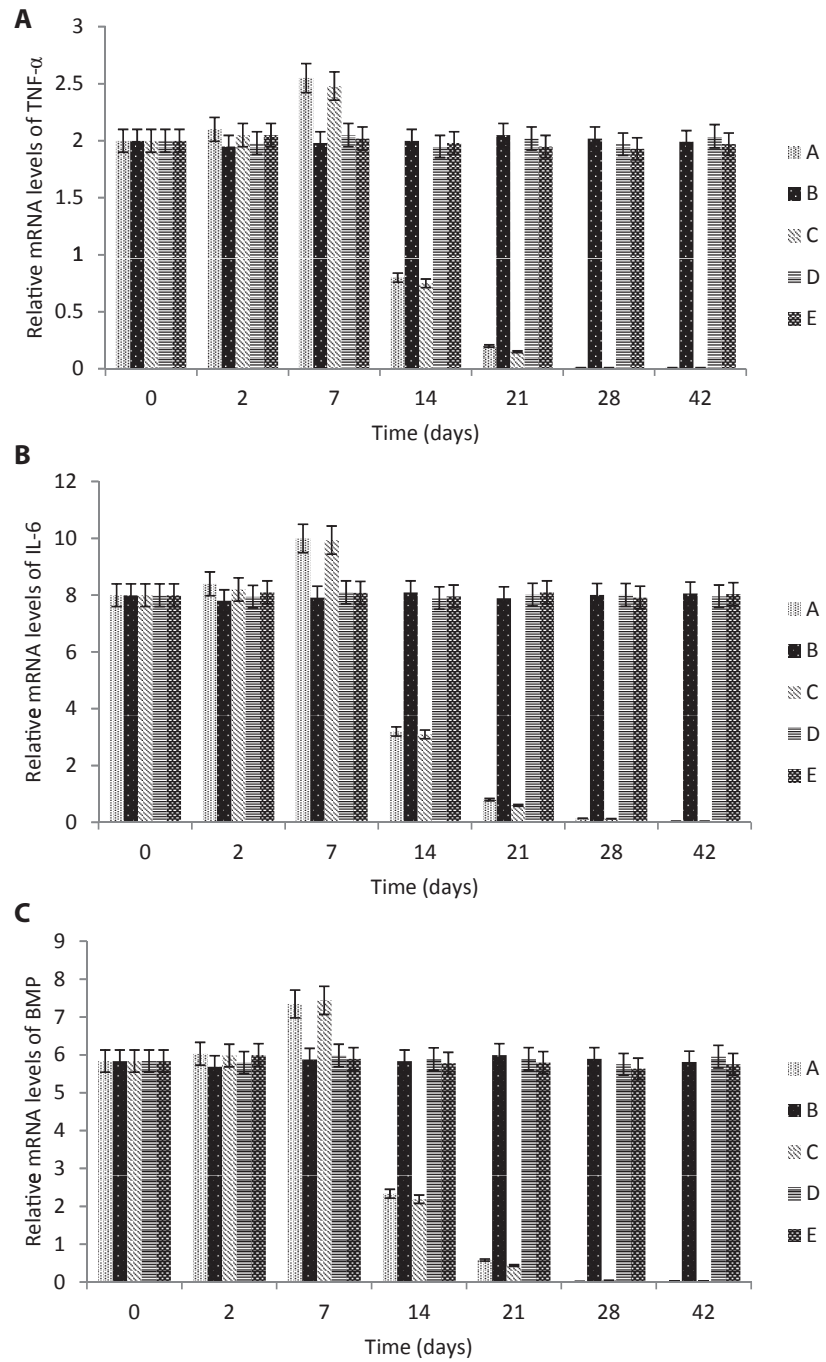

Fig. 3. Quantitative reverse transcriptase real-time PCR (qRT-PCR) analysis of the mRNA levels of TNF- $a, I L-6$ and BMP in peripheral blood

A - mRNA level of TNF- $a$; B - mRNA level of IL-6; C - mRNA level of BMP. Group A - experimental group, femoral fractures + splenectomy; group B - femoral fractures only; group C - splenectomy only; group D - femoral fracture + sham splenectomy; group E - sham fracture.

of TNF- $\alpha$, IL- 6 and BMP in the rats from group A and $C$ reached a peak at day 7 , and then decreased. For the rats without splenectomy (in groups B, D and E), the TNF- $\alpha$, IL-6 and BMP did not show significant changes (Fig. 4).

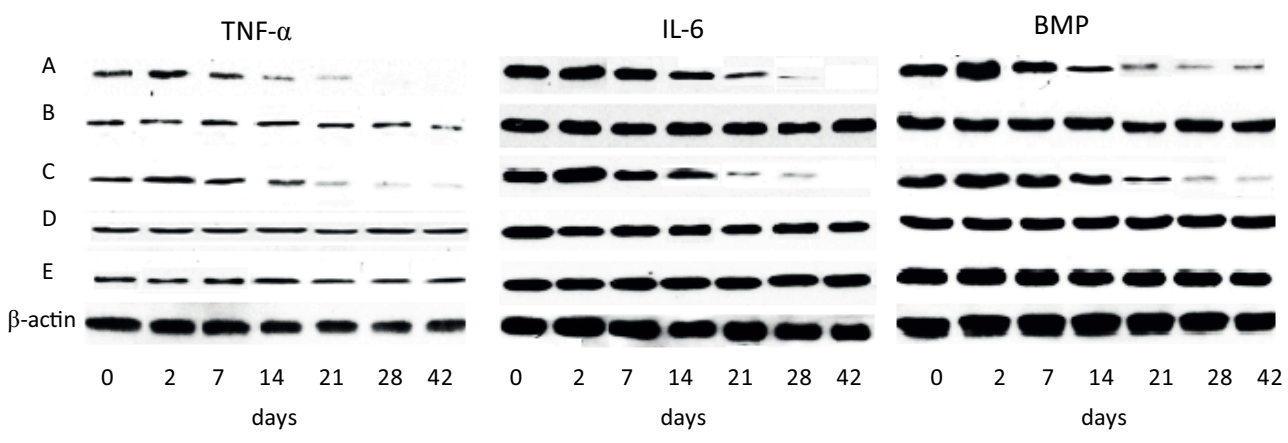

Fig. 4. Western blot analysis of the protein levels of TNF-a, IL-6 and BMP from different groups

Group A - experimental group, femoral fractures + splenectomy; group B - femoral fractures only; group C - splenectomy only; group $D$ - femoral fracture + sham splenectomy; group E - sham fracture. days days days 


\section{Discussion}

Abdominal injuries combined with fractures caused by the accident trauma result in splenectomy in many patients. The splenectomy group was significantly different from the fracture-operated-only group (Table 2), which demonstrated that splenectomy delays the fracture healing process.

The spleen is an important organ of immunity, containing antigen-presenting $\mathrm{T}$ cells and $\mathrm{B}$ cells, which produce cytokines like TNF- $\alpha$ or IL- 6 . There are a lot of cytokines involved in the process of fracture healing. After splenectomy, T lymphocyte subsets in the peripheral blood change. The number of helper $\mathrm{T}$ lymphocytes reduces and the number of suppressor $\mathrm{T}$ lymphocytes increases. Previous studies have shown that splenectomy leads to a reduction of CD4+ T cells and a reduction of TNF- $\alpha$ and IL- 6 produced by other organs. ${ }^{13,14}$ The spleen is involved in endotoxin-mediated generation of IL-6. IL-6 levels in dog plasma was reduced by $75 \%$ after splenectomy. In this study, in the first 2 weeks after splenectomy, mRNA expression of IL- 6 was significantly lower than normal.

TNF- $\alpha$ has been extensively studied in bone and cartilage metabolism, and it has been considered an important intermedia of osteoclasts for many years. ${ }^{15-17}$ This study showed that the TNF- $\alpha$ mRNA levels after splenectomy increased in the first 7 days and reached a peak on day 7 . High levels of TNF- $\alpha$ can promote osteoclast activity and inhibit osteoblast activity. Over time, the mRNA levels of $T N F-\alpha$ decreased significantly and became much lower than normal. According to a previous study, lack of the TNF- $\alpha$ signal caused a persistence of the cartilage healing tissue and delayed absorption of the mineralized cartilage tissue, which thereby delayed the original bone reconstruction. And it has been proven that BMP plays a pivotal role in the healing process. ${ }^{18}$ Another study showed that TNF- $\alpha$ can induce production of BMP-2. ${ }^{19}$ Our study found that splenectomy caused a decrease in the mRNA levels of BMP.

IL- 6 is a multifunctional cytokine which is produced by both lymphoid and non-lymphoid tissue cells. IL-6 receptors are found in the cell membrane of various cells, such as activated B cells, quiescent $\mathrm{T}$ cells, macrophages, osteoblasts, and osteoclasts, which is the material base of IL- 6 function. ${ }^{20}$ Many studies have shown that IL-6 plays an important role in bone formation and repair. IL- 6 can stimulate the production of the RANK ligand in osteoblasts and promote the transformation of peripheral blood mononuclear cells into bone cells. ${ }^{21}$ IL-6 can also induce the differentiation of osteoblast precursors, inhibit the formation of bone medium bone nodules and induce production of cathepsin $\mathrm{B}^{22-24}$ In the process of distraction osteogenesis, the osteoblasts, hematopoietic cells and cartilage cell growth-related cells can produce IL- $6 .{ }^{25} \mathrm{~A}$ fracture healing rat model has shown that in the process of cartilage reconstruction and cartilage ossification, increased production of IL-6 is observed. ${ }^{26,27}$ Thus, continued low mRNA expression of $I L-6$ after splenectomy in some way affects the expression of BMP, and results in a delay of the secondary bone reconstruction process.

In short, the fracture healing process is complex and many cytokines are involved. In this pilot study, we studied the trends of $T N F-\alpha, I L-6$ and $B M P$ mRNA levels after splenectomy. The underlying regulatory mechanism is unclear at present.

\section{Conclusions}

Changes in the immune function after splenectomy delayed the fracture healing process. The delay of the fracture healing after splenectomy was related to low-level expression of TNF- $\alpha$, IL- 6 and BMP.

\section{References}

1. Liu S, Lei J, Zeng Z, Zhang Y. Management of traumatic splenic rupture in adults: A single center's experience in Mainland China. Hepatogastroenterology. 2014;61:966-971.

2. Yang GE, Duan X, Lin D, et al. Rapamycin-induced autophagy activity promotes bone fracture healing in rats. Exp Ther Med. 2015; 10:13271333

3. Histing T, Heerschop K, Klein M, et al. Characterization of the healing process in non-stabilized and stabilized femur fractures in mice. Arch Orthop Trauma Surg. 2016;136(2):203-211. doi:10.1007/s00402015-2367-7

4. Schmidt-Bleek $\mathrm{K}$, Schell $\mathrm{H}$, Lienau J, et al. Initial immune reaction and angiogenesis in bone healing. $J$ Tissue Eng Regen Med. 2014;8: 120-130.

5. Lin HN, Cottrell J, O'Connor JP. Variation in lipid mediator and cytokine levels during mouse femur fracture healing. J Orthop Res. 2016;34(11):1883-1893. doi:10.1002/jor.23213

6. Fan H, Li TF, Gong N, Wang YX. Shanzhiside methylester, the principle effective iridoid glycoside from the analgesic herb Lamiophlomis rotata, reduces neuropathic pain by stimulating spinal microglial beta-endorphin expression. Neuropharmacology. 2016;101:98-109.

7. TNF-alpha accelerates bone fracture healing. Bonekey Rep. 2012; 1:100.

8. Uliana GN, Tambara EM, Baretta GA. Use of remifentanil to reduce propofol injection pain and the required propofol dose in upper digestive tract endoscopy diagnostic tests. Braz J Anesthesiol. 2015;65:437-444.

9. Farzandipour $M$, Sheikhtaheri A. Evaluation of factors influencing accuracy of principal procedure coding based on ICD-9-CM: An Iranian study. Perspect Health InfManag. 2009;6:5.

10. Williams CA, Hauser KW, Correia JA, Frias JL. Ascertainment of gastroschisis using the ICD-9-CM surgical procedure code. Birth Defects Res A Clin Mol Teratol. 2005;73:646-648.

11. Singh $M$, Nagrath $A R$, Maini PS. Changes in trabecular pattern of the upper end of the femur as an index of osteoporosis. J Bone Joint Surg Am. 1970;52:457-467.

12. Bookout AL, Mangelsdorf DJ. Quantitative real-time PCR protocol for analysis of nuclear receptor signaling pathways. Nucl Recept Signal. 2003;1:e012.

13. Karakantza M, Theodorou GL, Mouzaki A, Theodori E, Vagianos C, Maniatis A. In vitro study of the long-term effects of post-traumatic splenectomy on cellular immunity. Scand J Immunol. 2004;59: 209219.

14. Kimpel D, Dayton T, Fuseler J, et al. Splenectomy attenuates streptococcal cell wall-induced arthritis and alters leukocyte activation. Arthritis Rheum. 2003;48:3557-3567. 
15. Lieberman JR, Daluiski A, Einhorn TA. The role of growth factors in the repair of bone. Biology and clinical applications. J Bone Joint Surg Am. 2002;84-A(6):1032-1044.

16. Goldring SR, Gravallese EM. Mechanisms of bone loss in inflammatory arthritis: Diagnosis and therapeutic implications. Arthritis Res. 2000;2:33-37.

17. Nanes MS. Tumor necrosis factor-alpha: Molecular and cellular mechanisms in skeletal pathology. Gene. 2003;321:1-15.

18. Hou CH, Hou SM, Tang CH. Ultrasound increased BMP-2 expression via $\mathrm{PI} 3 \mathrm{~K}, \mathrm{Akt}, \mathrm{c}-\mathrm{Fos} / \mathrm{c}-J u n$, and AP-1 pathways in cultured osteoblasts. J Cell Biochem. 2009;106:7-15.

19. Lu Z, Wang G, Dunstan $C R$, et al. Activation and promotion of adipose stem cells by tumour necrosis factor-alpha preconditioning for bone regeneration. J Cell Physiol. 2013;228:1737-1744.

20. Dai Q, Qi X, Guo M. Interleukin 6 (IL-6) and bone resorption. Chin J Orthop. 1996;16:516-516.

21. Tanaka Y, Nakayamada S, Okada Y. Osteoblasts and osteoclasts in bone remodeling and inflammation. Curr Drug Targets Inflamm Allergy. 2005;4:325-328.
22. Itoh S, Udagawa N, Takahashi N, et al. A critical role for interleukin 6 family-mediated Stat3 activation in osteoblast differentiation and bone formation. Bone. 2006;39:505-512.

23. Hughes FJ, Howells GL. Interleukin 6 inhibits bone formation in vitro. Bone Miner. 1993;21:21-28.

24. Chae HJ, Ha KC, Lee GY, et al. Interleukin 6 and cyclic AMP stimulate release of cathepsin B in human osteoblasts. Immunopharmacol Immunotoxicol. 2007;29:155-172.

25. Cho TJ, Kim JA, Chung CY, et al. Expression and role of interleukin 6 in distraction osteogenesis. Calcif Tissue Int. 2007;80:192-200.

26. Kuroda S, Virdi AS, Dai Y, Shott S, Sumner DR. Patterns and localization of gene expression during intramembranous bone regeneration in the rat femoral marrow ablation model. Calcif Tissue Int. 2005;77:212-225.

27. Gerstenfeld LC, Cullinane DM, Barnes GL, Graves DT, Einhorn TA. Fracture healing as a post-natal developmental process: Molecular, spatial, and temporal aspects of its regulation. J Cell Biochem. 2003;88:873-884. 